\title{
The application of the EN ISO 52016 standard and its Italian National Annex to assess the heating and cooling needs of a reference office building
}

\author{
Franz Bianco Mauthe Degerfeld ${ }^{1, *}$, Ilaria Ballarini ${ }^{1}$, Giovanna De Luca $^{1}$, and Vincenzo \\ Corrado ${ }^{1}$ \\ ${ }^{1}$ Dipartimento Energia, Politecnico di Torino, Torino, Italy
}

\begin{abstract}
The EN ISO 52016-1 standard presents a new simplified dynamic calculation procedure, whose aim is to provide an accurate energy performance assessment without excessively increasing the number of data required. The Italian National Annex to EN ISO 52016-1, currently under development, provides some improvements to the hourly calculation method; despite many works can be found in literature on the hourly model of EN ISO 52016-1, the National Annexes application has not been sufficiently analysed yet. The aim of the present work is to assess the main improvements introduced by the Italian National Annex and to compare the main results, in terms of energy need for space heating and cooling. To this purpose, an existing building representative of the Italian office building stock in Northern Italy was selected as a case study. The energy simulations were carried out considering both continuous and reduced operation of the HVAC systems. The options specified in the Italian National Annex were firstly applied one by one, and then all together. The variation of the energy need compared to the international base procedure is finally quantified. For the premises and the scope above discussed, the present work is intended to enhance the standardisation activity towards the adoption of more accurate and trustable calculation methods of the building energy performance.
\end{abstract}

\section{Introduction}

In the last years, the issue of improving the energy efficiency of buildings paved the way for two different development paths of the building energy performance assessment: a detailed calculation method, aimed at reaching a high level of detail, and a more simplified one, instead addressed to the simplicity in its application. Regarding the latter, the recently introduced EN ISO 52016-1 [1] technical standard provides a simplified hourly dynamic calculation procedure aimed at providing a proper level of detail with a limited need of input data. To this purpose, several assumptions and simplifications were introduced and defined

\footnotetext{
* Corresponding author: franz.bianco@polito.it
} 
in the standard. Since the publication of the EN ISO 52016-1 hourly method, several studies analysed and deepened its simplifications in order to assess the deviation in comparison with actual measured data, or with the outcomes of more detailed procedures. Zakula et al. [2] analysed the effect of the use of constant properties for windows, highlighting the not negligible differences between the results of the simplified calculation method and those of the detailed dynamic method of TRNSYS, for most of the considered cases. Ballarini et al. [3] instead deepened the effect of the use of constant values for the surface heat transfer coefficient, showing significant variation between the EN ISO 52016-1 procedure and EnergyPlus.

To maximize its adaptability, the EN ISO 52016-1 standard provides the possibility for the National Annexes to define alternative procedures or specific choices that can be more suitable for the specific application. The Italian National Annex (NA) [4], which is currently under approval, defines several variations and implementations for different aspects of the building energy performance assessment. In particular, the main implementations concern the discretization of the building envelope components into a $\mathrm{R}-\mathrm{C}$ model, the calculation of the apparent sky temperature and the total solar energy transmittance, as well as the possibility of carrying out the calculation with thermal coupled zones.

Among the implementations specified in the Italian NA, to date only the improved procedure related to the R-C model definition has been analysed; this was performed by Mazzarella et al. [5] through comparisons with the exact analytic solution. It is thus crucial to broaden current knowledge of the improved modelling procedure introduced by the Italian NA, in order to clarify its effectiveness and the variation it produces when compared to the standard procedure. Therefore, the aim of this work is to take the first step in this direction. An office building was analysed by comparing, on a monthly basis, the building energy need resulting from the hourly method of the EN ISO 52016-1 standard procedure with that obtained assuming the Italian Annex new calculation procedures, applied one by one and all at once.

\section{Methodology}

\subsection{Description of the calculation model improvements (EN ISO 52016-1 Italian National Annex)}

Limited to the simplified hourly method of the building energy performance assessment, the main implementations of the Italian National Annex (NA) to the EN ISO 52016-1 standard are described in the following subsections.

\subsubsection{Calculation with thermally coupled or uncoupled thermal zones}

The EN ISO 52016-1 standard does not allow the coupling of different thermal zones, neglecting the possible exchanges of energy and mass between adjacent conditioned zones. Nevertheless, the calculation procedures for the coupling of adjacent thermally conditioned zones are described in Annex D [1]. For what concern the air flow exchanges, both monoand bi-directional air flows are considered. As for the heat flow through internal partitions, 
the temperature of the surface node calculated at the previous timestep is deployed as boundary condition for the calculation; in case the interaction between zones is significant, in order to avoid oscillations in the results derived from the temperature assumption, an iterative procedure with proper relaxation factors is to be preferred. Contrary to the European standard, the Italian NA allows the calculation with coupled thermally thermal zones by applying the aforementioned procedures.

\subsubsection{Discretization of the building envelope components into $R-C$ nodes}

In the EN ISO 52016-1 standard, each opaque element of the building is converted to a system of resistance-capacitance nodes (R-C), composed of up to five nodes. The areal heat capacity of each node is calculated as variable fraction of the total areal heat capacity, defined according to the qualitative mass distribution class to which each component belongs, as described in the standard. Five mass distribution classes are considered, and are described as follows: class I - with the mass concentrated at the internal side, class E - with the mass concentrated at the external side, class IE - with the mass divided over the internal and the external sides, class D - with the mass equally distributed, and class $\mathrm{M}$ - with the mass concentrated inside. The internode conductance is calculated assuming fixed portions of the total thermal resistance of the component, without taking into account the effective distribution of the thermal properties in the component layers.

The Italian NA presents instead a more detailed procedure for the discretization of the opaque components, which is tailored on the actual distribution of the physical and thermal properties of the single layers of the component. This procedure, presented and validated by Mazzarella et al. [5], assigns a variable number of nodes to each layer, determined through Equations 1 and 2 .

$$
\begin{gathered}
N_{\mathrm{cn}}=\max \left\{1 ; \operatorname{int}\left[\left(F_{\text {Oref }} / F_{O}\right)^{0.5}+0.999999\right]\right\} \\
F_{O}=\Delta t \cdot \lambda /(\rho \cdot c) / d^{2}
\end{gathered}
$$

where $F_{O}$ ref is the reference Fourier number - equal to 0.5 - and for each layer material, $F_{O}$ is the Fourier number, $\lambda$ is the thermal conductivity in $\mathrm{W} /(\mathrm{m} \cdot \mathrm{K}), \rho$ is the density in $\mathrm{kg} / \mathrm{m}^{3}$, $c$ is the thermal capacity by unit of mass expressed in $\mathrm{J} /(\mathrm{kg} \cdot \mathrm{K})$, and $d$ is the thickness in $\mathrm{m}$.

To each node thus defined, a portion of layer mass and thermal resistance is assigned as shown in Fig. 1. Two nodes are also associated to the external and internal surfaces, respectively, in both the calculation methods. However, contrary to the EN ISO 52016-1 standard procedure, no heat capacity is associated to the surface nodes in the Italian NA procedure. 


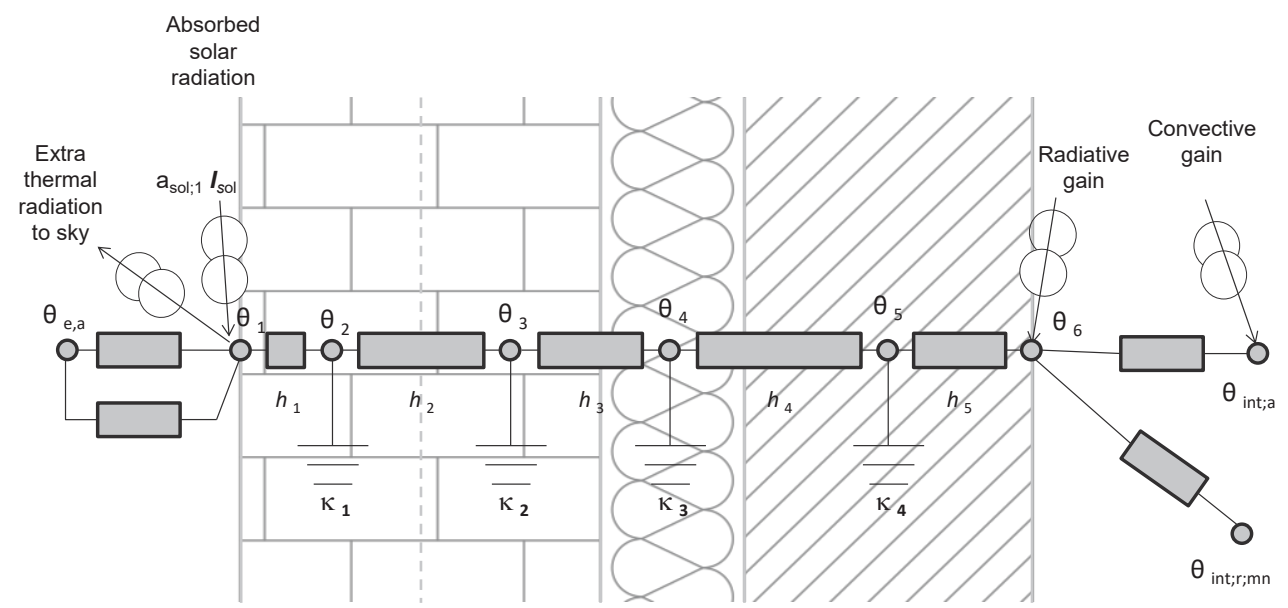

Fig. 1. Illustration of the nodes distribution in an opaque component according to the Italian NA.

\subsubsection{Difference between external air temperature and sky temperature}

In the EN ISO 52016-1 procedure, the long wave radiation exchanged between the external surfaces of the building envelope and the sky is calculated separately from the other radiant exchanges that take place between the components and the surrounding environment. This is known as the extra thermal radiation to the sky, $\Phi_{\text {sky, }}$ and is calculated according to Equation 3.

$$
\Phi_{\text {sky }}=F_{\text {sky }} \cdot h_{\text {re }} \cdot \Delta \theta_{\text {sky }}
$$

where $F_{\text {sky }}$ is the view factor to the sky, $h_{\text {re }}$ is the external radiative surface heat transfer coefficient expressed in $\mathrm{W} /\left(\mathrm{m}^{2} \cdot \mathrm{K}\right), \Delta \theta_{\text {sky }}$ is the average difference between the air temperature, and the apparent sky temperature in $\mathrm{K}$. While this latter is determinate as a fixed value (equal to $11 \mathrm{~K}$ for the intermediate climatic region) in the standard procedure, an hourly calculation procedure is instead presented in the Italian NA (Equation 4).

$$
\Delta \theta_{\text {sky }}=\theta_{\mathrm{e}}-\left(18-51.6 \cdot \mathrm{e}^{-p v e / 1000}\right)
$$

where $\theta_{\mathrm{e}}$ is the external temperature in ${ }^{\circ} \mathrm{C}$, and $p_{v e}$ is the external vapour pressure in Pa.

\subsubsection{Correction and weighting factor for $g$-value for non-scattering and scattering transparent glazing and blinds}

In both the calculation methods, a weighted time average value of the total solar energy transmittance ( $g$ or $S H G C$ ) is assumed over the simulation period, following Equation 5.

$$
g_{\mathrm{gl}}=F_{\mathrm{w}} \cdot g_{\mathrm{gl}, \mathrm{n}}
$$

where $g_{\mathrm{gl}}$ is the total solar energy transmittance corrected for the angle of incidence, $g_{\mathrm{gl}, \mathrm{n}}$ is the total solar energy transmittance at normal incidence, and $F_{\mathrm{w}}$ is a correction factor for nonscattering glazing. This latter, while in EN ISO 52016-1 is assumed equal to 0.9 and constant 
over the simulation period, in the Italian NA is assumed variable on a time-step basis; it is calculated as in Equations 6 and 7 [6].

$$
\begin{gathered}
F_{\mathrm{W}}=\frac{F_{\mathrm{W}, \mathrm{diff}} I_{\mathrm{sol}, \mathrm{diff}}+F_{\mathrm{W}, \mathrm{dir}} \cdot I_{\mathrm{sol}, \mathrm{dir}} \cdot F_{\mathrm{sh}, \mathrm{obs}, \mathrm{wi}}}{I_{\mathrm{sol}, \mathrm{diff}}+I_{\mathrm{sol}, \mathrm{dir}}} \\
F_{\mathrm{W}, \mathrm{dir}}=1-8 \cdot z^{5.2+0.7 \cdot q}-(0.25 / q) \cdot z^{2}+(7+0.25 / q) \cdot \\
\cdot z^{[(5.26+0.06 \cdot p)+(0.73+0.04 \cdot p) \cdot q]}
\end{gathered}
$$

where $F_{\text {w,diff }}$ and $F_{\text {w,dir }}$ are the correction factors for the diffuse (assumed equal to 0.8 ) and the beam incident solar irradiance, respectively, $I_{\text {sol, diff }}$ and $I_{\text {sol, dir }}$ are the diffuse and beam incident

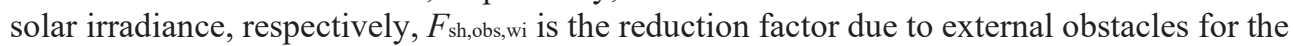
beam incident solar irradiance, $z$ is the ratio between the angle of incidence of direct solar radiation in degrees and a right angle, $q$ is a coefficient referred to the glazing coating typology, and $p$ is the number of glazing panes.

\subsection{Workflow}

As introduced, a case study approach was used to address the research goals. Firstly, an energy model implementing the EN ISO 52016-1 standard method (referred as Annex B in the following subsections) was created for the considered case study. Then, the improved modelling options introduced by the Italian NA were implemented to the standard model one at a time, and the effects of each option on the energy need of the case study were assessed. In particular, the following different modelling options were considered: (i) the discretization model of the building envelope component (referred as NA conduction model), (ii) the calculation of the apparent sky temperature (referred as NA sky temperature), and (iii) the calculation of the corrective coefficient of the window solar transmission factor (referred as NA exposure factor). Moreover, the effect of all the NA improved modelling options was evaluated as well (simulation referred as NA). To guarantee a general validity of the outcomes, both a continuous and an intermittent operation of the heating and cooling systems was considered for the case study.

\subsubsection{The EN ISO 52016-1 spreadsheet}

The simulation presented in the previous paragraph were performed by means of the EPB MS Excel spreadsheet tool [7], which employs a combination of formulas and algorithms written in Visual Basic and run through macros. This was modified and implemented by the Authors to make it applicable to the case study considered. In particular, besides the modelling procedures introduced by the Italian NA, the possibility of the computation of multiple zones at the same time and the calculation of the heat exchanges with thermally unconditioned zones were also implemented in the tool.

Due to the high transparency of the model inputs and algorithms, the main advantage in using this tool is the possibility to completely control the entire process and the opportunity to obtain and compare partial and intermediate results. In terms of results processing and parameters comparison, the spreadsheet tool proved to be more useful than the majority of 
commercial software, which often act as "black boxes" where the only control that the user has is on the inputs and on some predetermined output data.

\section{Case study}

\subsection{Description of the building}

The considered case study is an existing office building, built in 1986 (Fig. 2), characterised by an unconditioned basement and seven above ground conditioned storeys. Its geometrical characteristics were simplified for the sake of the current study.

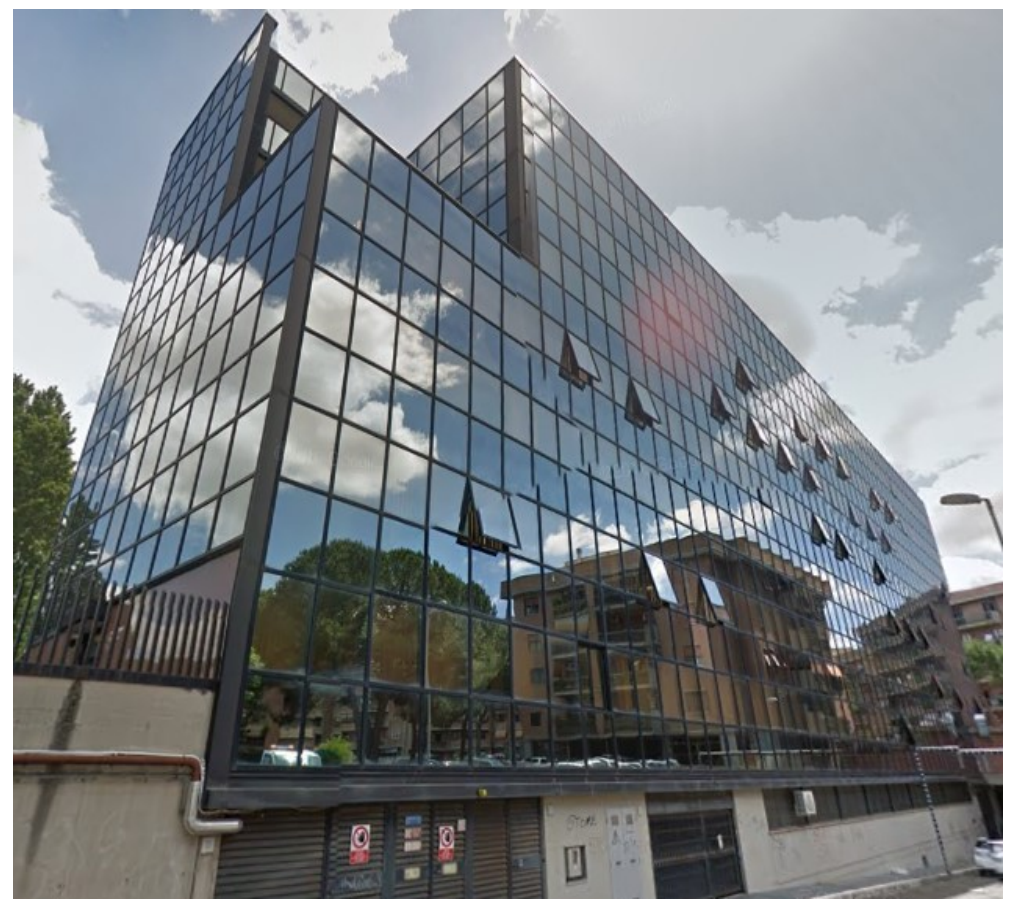

Fig. 2. Image of the building.

As far as the building envelope components are concerned, the case study has a poorly insulated building envelope. In particular, the external walls of the North-West and SouthEast façades, as well as of the North-East façade on the ground floor, have a thickness of about $25 \mathrm{~cm}$ and are characterized by two rows of perforated bricks separated by an air gap. The external layer of the walls is plaster on the ground floor $\left(U_{\text {wall }}=1.24 \mathrm{~W} \cdot \mathrm{m}^{-2} \cdot \mathrm{K}^{-1}\right.$, $\kappa_{\text {wall }}=52 \mathrm{~kJ} \cdot \mathrm{m}^{-2} \cdot \mathrm{K}^{-1}$ ), while upstairs the walls are externally covered with glass panels $\left(U_{\text {wall }}=1.26 \mathrm{~W} \cdot \mathrm{m}^{-2} \cdot \mathrm{K}^{-1}, \kappa_{\text {wall }}=51 \mathrm{~kJ} \cdot \mathrm{m}^{-2} \cdot \mathrm{K}^{-1}\right)$. The external walls of the South-West façades, as well as of the North-East façade on the floors above the ground, are spandrel-type walls composed of plasterboard and mineral insulation, externally covered with glass panels $\left(U_{\text {wall }}=0.74 \mathrm{~W} \cdot \mathrm{m}^{-2} \cdot \mathrm{K}^{-1}, \kappa_{\text {wall }}=42 \mathrm{~kJ} \cdot \mathrm{m}^{-2} \cdot \mathrm{K}^{-1}\right)$. The walls of the stairwells are made of reinforced concrete, also covered externally with glass panels $\left(U_{\text {wall }}=3.39 \mathrm{~W} \cdot \mathrm{m}^{-2} \cdot \mathrm{K}^{-1}, \kappa_{\text {wall }}=\right.$ $\left.66 \mathrm{~kJ} \cdot \mathrm{m}^{-2} \cdot \mathrm{K}^{-1}\right)$. As for the horizontal opaque components, the floor that separates the 
unconditioned basement and the first floor, as well as the roof, are made of load-bearing slabs or brick blocks and concrete substrates. In particular, the internal slabs have $29 \mathrm{~cm}$ thickness and a plastic coating $\left(U_{\text {floor }}=1,41 \mathrm{~W} \cdot \mathrm{m}^{-2} \cdot \mathrm{K}^{-1}, \kappa\right.$ floor $\left.=63 \mathrm{~kJ} \cdot \mathrm{m}^{-2} \cdot \mathrm{K}^{-1}\right)$, while the flat roof has $36 \mathrm{~cm}$ thickness and ceramic tile coating $\left(U_{\text {roof }}=1.81 \mathrm{~W} \cdot \mathrm{m}^{-2} \cdot \mathrm{K}^{-1}, \kappa_{\text {roof }}=69 \mathrm{~kJ} \cdot \mathrm{m}^{-2} \cdot \mathrm{K}^{-1}\right)$. The windows are characterized by a double glazing (DGU) with metal frame $\left(U_{\text {window }}=3.20\right.$ $\left.3.26 \mathrm{~W} \cdot \mathrm{m}^{-2} \cdot \mathrm{K}^{-1}, g_{\mathrm{gl}, \mathrm{n}}=0.85\right)$. Neither shutters nor solar shading devices are installed.

\subsection{Calculation assumptions and boundary conditions for simulations}

The case study was considered to be sited in Milan. The climatic data used for the energy performance evaluations refer to the Typical Meteorological Year, elaborated by the Italian Thermo-technical Committee (CTI) for the considered city.

The building was considered to be divided into the five thermal zones, defined as follows and shown in Fig. 3:

- $\quad$ thermal zone 1: open offices on the $1^{\text {st }}$ floor;

- thermal zone 2: North-oriented single offices from the $1^{\text {st }}$ to the $7^{\text {th }}$ floor;

- thermal zone 3: South-oriented single offices from the $1^{\text {st }}$ to the $7^{\text {th }}$ floor;

- $\quad$ thermal zone 4: corridors from the $1^{\text {st }}$ to the $7^{\text {th }}$ floor;

- thermal zone 5: toilets from the $1^{\text {st }}$ to the $7^{\text {th }}$ floor;

The basement floor and the stairs were assumed to be unconditioned with a default ventilation rate $(0.5 \mathrm{vol} / \mathrm{h})$ constant over the calculation period. A standard user behaviour was considered for the conditioned thermal zones, and the data were derived from the draft of the Italian National Annex to the EN 16798-1:2019 [8] technical standard. The user behaviour data assumed in the calculation are shown in Table 1.

Table 1. Summary of user data.

\begin{tabular}{|c|c|c|c|c|}
\hline \multirow{2}{*}{ Parameter } & \multicolumn{4}{|c|}{ Thermal zone } \\
\hline & 1 & 2 and 3 & 4 & 5 \\
\hline Number of people per unit of floor area $\left[\mathrm{m}^{-2}\right]$ & 0.12 & 0.05 & 0.00 & 0.07 \\
\hline Total heat power released by a person [W] & \multicolumn{4}{|c|}{118} \\
\hline Convective heat power released by a person [W] & \multicolumn{4}{|c|}{41} \\
\hline Radiative heat power released by a person [W] & \multicolumn{4}{|c|}{39} \\
\hline Latent heat power released by a person [W] & \multicolumn{4}{|c|}{38} \\
\hline Moisture produced by a person $\left[\mathrm{g} \cdot \mathrm{h}^{-1}\right]$ & \multicolumn{4}{|c|}{54.7} \\
\hline Mean lighting and appliance heat gains $\left[\mathrm{W} \cdot \mathrm{m}^{-2}\right]$ & \multicolumn{2}{|c|}{27} & \multicolumn{2}{|c|}{12} \\
\hline Mean appliance moisture production $\left[\mathrm{g} \cdot \mathrm{h}^{-1} \cdot \mathrm{m}^{-2}\right]$ & 4.1 & 6.2 & 0 & 0 \\
\hline Supply air flow rate $\left[\mathrm{m}^{-3} \cdot \mathrm{h}^{-1} \cdot \mathrm{m}^{-2}\right]$ & 1.80 & 1.07 & 1.00 & 0.03 \\
\hline$T_{\mathrm{op}}$ in occupied hours for heating $\left[{ }^{\circ} \mathrm{C}\right]$ & 20 & 20 & 16 & 20 \\
\hline$T_{\mathrm{op}}$ in occupied hours for cooling $\left[{ }^{\circ} \mathrm{C}\right]$ & 26 & 26 & 25 & 26 \\
\hline Minimum $T_{\mathrm{op}}$ in unoccupied hours $\left[{ }^{\circ} \mathrm{C}\right]$ & \multicolumn{4}{|c|}{16} \\
\hline Maximum $T_{\text {op }}$ in unoccupied hours $\left[{ }^{\circ} \mathrm{C}\right]$ & \multicolumn{4}{|c|}{32} \\
\hline
\end{tabular}


- $1^{\text {st }}$ FLOOR

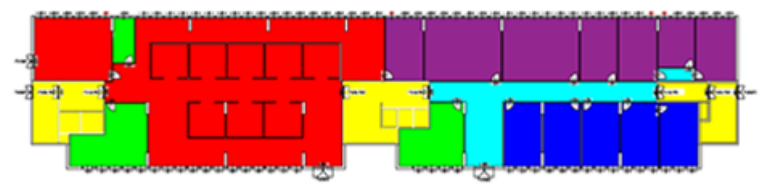

$\cdot 2^{\text {nd }}$ to $7^{\text {th }}$ FLOOR

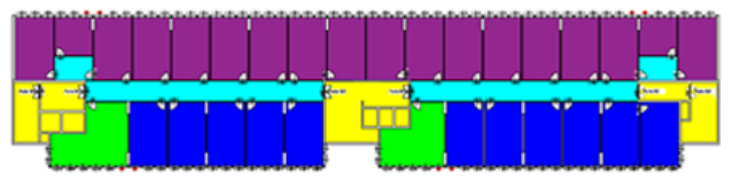

Thermal zone 1

Thermal zone 2

Thermal zone 3

Thermal zone 4

Thermal zone 5

Stairs

Fig. 3. Building storeys and thermal zones.

\section{Results and discussion}

In the present section, the effects of the improved options introduced by the Italian NA on the building energy needs for space heating and cooling are evaluated. In particular, the thermal needs predicted with the EN ISO 52016-1 original approach (referred as Annex B) are compared to the ones obtained with the implementations of the NA improved modelling. In particular, this comparison in presented on a monthly basis in Fig. 4 and Fig. 5, for the continuous and the intermittent operation of the heating and cooling systems, respectively. It is possible to observe that the extent of the energy needs variation due to the implementation of the improved NA modelling options is consistent in both the continuous and the intermittent regime. Therefore, the analysis of the results is mainly focused on the case study with the continuous operation of the heating and cooling systems. The monthly percentage variations of the thermal needs $\Delta Q_{\mathrm{H} / \mathrm{C} \text {,nd }}$ (each simulation case compared to the EN ISO 52016-1 original approach) are presented in Table 2; positive values of $\Delta Q_{\mathrm{H} / \mathrm{C} \text {,nd }}$ indicate an increase of the absolute value of energy need. 


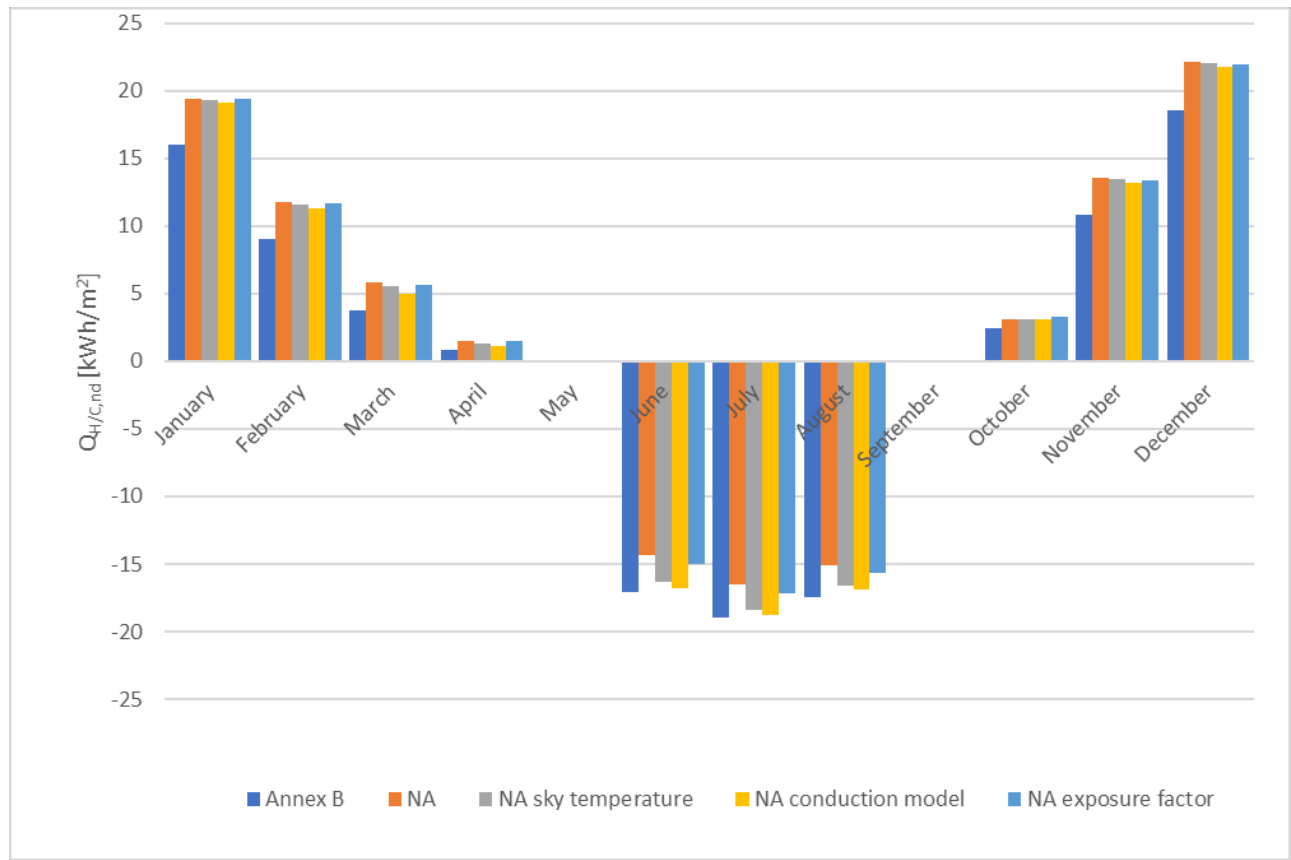

Fig. 4. Thermal energy need for heating and cooling under the hypothesis of EN ISO 52016-1 and the Italian National Annex (continuous regime).

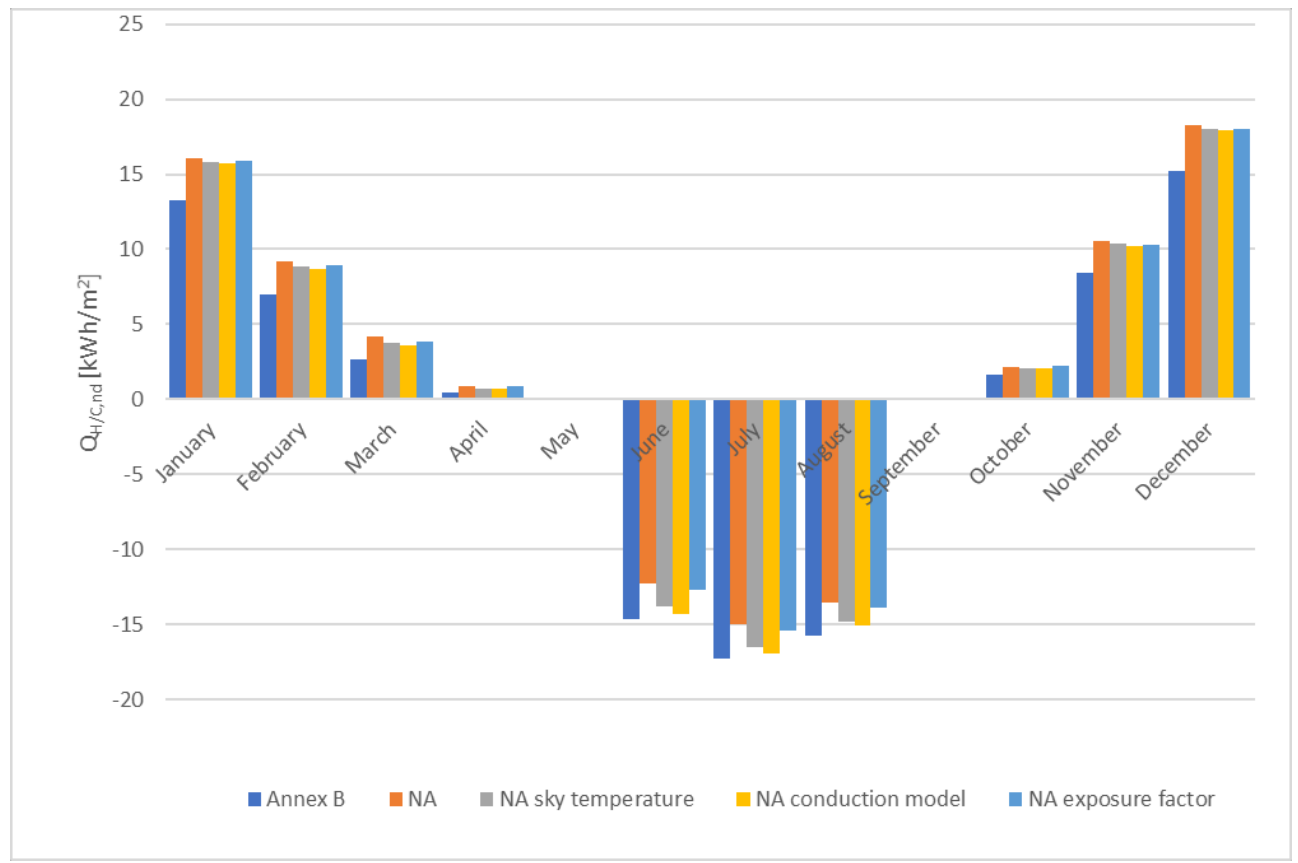

Fig. 5. Thermal energy need for heating and cooling under the hypothesis of EN ISO 52016-1 and the Italian National Annex (intermittent regime). 
Table 2. $\Delta Q_{H / C, \text { nd }}$ for the continuous operation of thermal systems.

\begin{tabular}{|c|c|c|c|c|}
\hline Period & NA & $\begin{array}{c}\text { NA sky } \\
\text { temperature }\end{array}$ & $\begin{array}{c}\text { NA conduction } \\
\text { model }\end{array}$ & $\begin{array}{c}\text { NA exposure } \\
\text { factor }\end{array}$ \\
\hline January & $21 \%$ & $21 \%$ & $20 \%$ & $21 \%$ \\
\hline February & $30 \%$ & $28 \%$ & $24 \%$ & $29 \%$ \\
\hline March & $53 \%$ & $46 \%$ & $32 \%$ & $49 \%$ \\
\hline April & $82 \%$ & $62 \%$ & $43 \%$ & $85 \%$ \\
\hline May & - & - & - & - \\
\hline June & $-16 \%$ & $-4 \%$ & $-2 \%$ & $-12 \%$ \\
\hline July & $-13 \%$ & $-3 \%$ & $-1 \%$ & $-10 \%$ \\
\hline August & $-14 \%$ & $-5 \%$ & $-3 \%$ & $-11 \%$ \\
\hline September & - & - & - & - \\
\hline October & $26 \%$ & $24 \%$ & $24 \%$ & $32 \%$ \\
\hline November & $25 \%$ & $25 \%$ & $21 \%$ & $24 \%$ \\
\hline December & $19 \%$ & $19 \%$ & $17 \%$ & $18 \%$ \\
\hline Year (Heating) & $26 \%$ & $24 \%$ & $21 \%$ & $25 \%$ \\
\hline Year (Cooling) & $-14 \%$ & $-4 \%$ & $-2 \%$ & $-11 \%$ \\
\hline
\end{tabular}

Generally, the improved modelling options introduced by the Italian NA lead to an increase in the energy need for heating. The extent of the increase is consistent for both the improved methods applied one at a time $(+24 \%,+21 \%$ and $+25 \%$, respectively for the NA sky temperature, the NA conduction model and NA exposure factor on an yearly-basis) and for the NA case $(+26 \%)$. On the other hand, a decrease in the energy need for cooling is observed. In this case, the cooling thermal need slightly decreases for the NA sky temperature and the NA conduction model cases $(-4 \%$ and $-2 \%$, respectively), while higher variations are observed for the NA exposure factor $(-11 \%)$ and the NA cases $(-14 \%)$.

As far as the determination of the apparent sky temperature is concerned, the implementation of the NA calculation model shows an increase of the heating energy need and a decrease of the cooling one, correlated to an increase of the heat transmission from the building envelope to the external environment. This is due to the fact that the annual average difference between the apparent sky and the external air temperature obtained by means of the Italian NA formulation $(13.2 \mathrm{~K})$ is higher than the reference value of $11 \mathrm{~K}$.

The exposure factor $\left(F_{\mathrm{W}}\right)$ values calculated with the Italian NA procedure are for the majority of the calculation period lower than the default value 0.9 . In fact, while the maximum values can reach $0.90-0.95$, depending on the exposure of the window, the minimum values drop to a range between 0.36 and 0.76 leading to mean annual values between 0.77 and 0.82 . Since this factor is directly applied to the solar total energy transmittance, a decrease in the $F_{\mathrm{W}}$ value causes a reduction of the solar radiation entering the building, and thus of the solar heat gains, leading to an increase in the energy need for heating, and a decrease in the cooling one. 
The implementation of all the improved NA modelling options shows not negligible variation in the results. Their effect on the energy needs for heating and cooling is relevant in both hourly and annual calculation especially for the energy needs for heating.

\section{Conclusion}

In the present study, the influence of the implementation of the Italian National Annex to the EN ISO 52016-1 hourly method on the energy needs of an existing office building was assessed. Considerable variations in the energy need for heating were observed for both NA improved models applied separately and for their combined application. Slightly lower variations were instead obtained in the energy needs for cooling by applying the NA sky temperature determination, as well as the envelope component discretization approach. The use of solar angle and time dependent correction factors for the total solar energy transmittance of glazing proved instead to be the most influencing modelling option on the cooling thermal needs.

The implementation of the improved modelling options introduced by the Italian National Annex are decisive for an accurate determination of the building energy needs. Further works will be focused on the evaluation of the Italian National Annex improvements under different assumptions, such as different building use categories and climatic zones.

\section{Acknowledgment}

The research for this paper was performed by implementing a tool developed by the EPB Center and made available within a cooperation agreement with the Department of Energy of Politecnico di Torino.

\section{References}

1. European Committee for Standardization, EN ISO 52016-1 Energy performance of buildings - Energy needs for heating and cooling, internal temperatures and sensible and latent heat loads - Part 1: Calculation procedures (2017)

2. T. Zakula, M. Bagaric, N. Ferdelji, B. Milovanovic, S. Mudrinic, and K. Ritosa. Comparison of dynamic simulations and the ISO 52016 standard for the assessment of building energy performance, Applied Energy, Vol. 254, 113553 (2019)

3. I. Ballarini, A. Costantino, E. Fabrizio, and V. Corrado. A Methodology to Investigate the Deviations between Simple and Detailed Dynamic Methods for the Building Energy Performance Assessment, Energies, Vol. 13, No. 23, 6217 (2020)

4. Comitato Termotecnico Italiano, Draft of Italian National Annex to EN ISO 52016-1, https:/www.cti2000.it/index.php?controller $=$ documenti\&action $=$ schedaAllMsg\&id $=62$ 539\& tipodoc $=4$, restricted document (2021)

5. L. Mazzarella, R. Scoccia, P. Colombo, and M. Motta. Improvement of EN ISO 52016-1:2017 hourly heat transfer thought a wall assessment: the Italian National Annex, Energy and Buildings, Vol. 210, 109758 (2020)

6. J. Karlsson, and A. Roos. Modelling the angular behaviour of the total solar energy transmittance of windows. Solar Energy, Vol. 69, No. 4, pp. 312-329 (2000)

7. EPB Center, Demo (EN) ISO 52016-1 (energy needs heating and cooling, internal temperatures and loads), https://epb.center/documents/demo-en-iso-52016-1/ (2019) 
8. European Committee for Standardization, EN 16798-1 Energy performance of buildings - Ventilation for buildings - Part 1: Indoor environmental input parameters for design and assessment of energy performance of buildings addressing indoor air quality, thermal environment, lighting and acoustics - Module M1-6 (2019) 